\title{
Logical form and logical space in Wittgenstein's Tractatus
}

\author{
Oliver Thomas Spinney ${ }^{1}$
}

Received: 17 December 2020 / Accepted: 22 October 2021 / Published online: 18 February 2022

(c) The Author(s) 2022

\begin{abstract}
In this article I offer a novel explanation of Wittgenstein's claim, in his Tractatus, that to represent the logical form of a proposition would require our being positioned outside of logic. The account here presented aims to exploit a connection, widely noticed, between the logical forms of objects and those of the propositions in which the names of those objects figure. I show that the logical forms of propositions may, on Wittgenstein's view, be identified with places in logical space, and that places in logical space are reducible to the forms of both objects and their names. I argue, though, that according to Wittgenstein the representation of a proposition's logical form would require the existence of a place in logical space not so reducible. I conclude that on Wittgenstein's position, the attempt to represent logical forms cannot, therefore, succeed.
\end{abstract}

Keywords Wittgenstein · Tractatus - Logical form · Propositions · Representation · Logical space

\section{Logical form}

\subsection{Objects}

Wittgenstein writes. ${ }^{1}$

Propositions can represent the whole of reality, but they cannot represent what they must have in common with reality in order to be able to represent it - logical form.

\footnotetext{
1 I would like to thank Fraser MacBride for both reading and commenting on several earlier drafts, as well as for the many invaluable conversations we have had concerning the present article. I would also like to thank two anonymous referees from this journal for their generous and useful comments.
}

Oliver Thomas Spinney

oliver.spinney@postgrad.manchester.ac.uk

1 The University of Manchester, Manchester, UK 
In order to be able to represent logical form, we should have to be able to station ourselves with propositions somewhere outside logic, that is to say outside the world. (4.12)

In the sections which follow I aim to provide an explanation of precisely why, in order that logical form be represented, we should have to station ourselves, per impossibile, 'somewhere outside logic'. It is important at the outset that I qualify the following discussion with the proviso that I do not take my interpretation of Wittgenstein's use of the word 'form' to wholly exclude the possibility of identifying alternative usages. Indeed, it is eminently possible that Wittgenstein employs the relevant word in more than one way. I have located one such use in order to interpret 4.12. Furthermore, I do not take the following interpretation of remark 4.12 to exhaust Wittgenstein's reasons for asserting the relevant remark. I therefore endorse Roger White's claim that 'Wittgenstein is convinced of his key positions not so much because there is a single argument that establishes them as because several different elements in his thinking converge on them.' (2006: p. 39). Consequently, I do not aim to suggest that the route I describe towards understanding remark 4.12 excludes the possibility of other such routes. $^{2}$

Central to my explanation will be the conclusion that the logical form of a proposition is not an object and may not therefore be named. It is vital then that we begin with an investigation into Wittgenstein's conception of an object. Specifically, I am concerned to describe the relationship between the forms of objects and their names. Of objects, Wittgenstein says 'The possibility of its occurring in states of affairs is the form of an object' (2.0141). Furthermore, 'It is essential to things that they should be possible constituents of states of affairs' (2.011). The form of an object is, therefore, the possibility of its occurring in a state of affairs. Wittgenstein says that 'A state of affairs (a state of things) is a combination of objects (things)' (2.01); states of affairs are combinations of objects. For an object to occur in a state of affairs is, therefore, for it to occur in a state of affairs as combined with other objects. The form of an object is, we may conclude, its combinatorial potential. In other words, the form of an object is its potential for combining with other objects in states of affairs.

In the Tractatus Wittgenstein is clear that names mean, or serve as representatives of, objects $(3.203 ; 3.22)$. In the Notebooks Wittgenstein stakes out the following relationship between the forms of objects and the names designating them ${ }^{3}$ :

If, e. g., I call some rod "A", and a ball "B", I can say that A is leaning against the wall, but not B. Here the internal nature of $\mathrm{A}$ and $\mathrm{B}$ comes into view.

A name designating an object thereby stands in a relation to it which is wholly determined by the logical kind of the object and which signalises that logical kind. (1961a: p. 70)

Where ' $A$ ' stands for a rod, and ' $B$ ' stands for a ball, it makes sense to say, ' $A$ is leaning against the wall', but not to say, ' $B$ is leaning against the wall', according

\footnotetext{
2 See, for instance, Black (1964: p. 188), Kenny (1973: p. 53), McGuinness (2002a: p. 68), Morris (2008: p. 151), Pears (1987: p. 7), and Sullivan (2001: p. 110).

3 This is not to suppose that 'A' and 'B' here count as genuine names, by the lights of the Tractatus, but only that they are being treated as such for the purposes of this discussion concerning category errors.
} 
to Wittgenstein. Wittgenstein says that this consideration brings the 'internal nature' of $A$ and $B$ into view. Where Wittgenstein, in the Notebooks, describes the internal nature of $A$ and $B$ as coming into view, he is chiefly concerned with their form or combinatorial potential. ${ }^{4}$ In other words, by observing the difference in significance between the two statements mentioned, we arrive at a firmer understanding of the combinatorial capabilities possessed by the objects named. The sentence ' $B$ is leaning against a wall' commits a category error because $B$ is not the right sort of thing to do any leaning. ${ }^{5} B$ may not stand in the relation of leaning to a wall, and the sign ' $B$ ' may not stand in a significant relation to the words 'leaning against the wall'. This combinatorial limitation of both $B$ and ' $B$ ' is, in Wittgenstein's view, made clear to us through our recognition of the relevant category error. An object and its name, then, share combinatorial capabilities as well as limitations. ${ }^{6}$ This sharing of combinatorial possibilities constitutes a relation in which the object and its name stand to one another. This relation, Wittgenstein says, 'signalises' the 'logical kind' of the object; the logical kind of an object is 'signalled' by a relation of shared combinatorial possibilities in which it stands to its name. The logical kind of an object is very plausibly its form ${ }^{7}$; consequently, we may draw the conclusion that the form of an object is signalled by the relation of shared combinatorial possibilities in which it stands to its name. In other words, the relation of sharing combinatorial possibilities, in which names and objects stand to one another, signals the logical kind of objects, on Wittgenstein's view.

Earlier in the Notebooks Wittgenstein remarks that 'Names signalise what is common to a single form and a single content.-Only together with their syntactical use do they signalise one particular logical form' (1961a: p. 53, emphasis original). Our grasp of the logical form of an object is achieved through our attending to the 'syntactical use' of that object's name. Elsewhere Wittgenstein describes syntax as 'rules for manipulation of symbols' (1961b: p. 116). Attending to the syntactical use of a name, then, involves grasping the ways in which that name may be 'manipulated' according to certain rules. We have seen, above, Wittgenstein emphasise the importance of appreciating category errors for grasping the forms of objects. Wittgenstein includes, it seems, in his conception of attending to the syntactical use of a name, that of attending to the syntactical misuse of a name. We must observe both legitimate and illegitimate manipulations in order that the form of an object be revealed to us. We achieve a grip on the combinatorial possibilities an object shares with its name, and therefore the form of the object, through our appreciating the ways in which that

\footnotetext{
4 This entry presents a challenge to Brian McGuinness' claim that Wittgenstein construes type differences principally in terms of adicity: 'All [Wittgenstein's] examples of type-differences, of differences of logical form, are of the order of the difference between $n$-placed predicates and $n+1$-placed predicates, or between propositions, facts and things.' (2002a: p. 74); see also McGuinness (80). McGuinness, while claiming that Wittgenstein 'overlooks or neglects' (74) the possibility of items differing in form without their names differing in adicity claims that '[Wittgenstein] never mentions that ordinary language does not distinguish between property-words of different type, though this, one would imagine, would be a more abundant source of confusions.' (74). Wittgenstein clearly does recognise that ordinary language begets confusion through its employment of words sharing grammatical categories while differing with respect to the combinatorial potential of the items they refer to.

5 See Malcolm (1986: p. 1).

6 See Malcolm (1986: pp. 4; 14).

7 See Hacker (1986: pp. 19-20).
} 
name may or may not significantly combine with others. The 'signalling' relation of shared combinatorial potential, in which objects and names stand to one another, is grasped through our attending to the possibilities for combination possessed by names. Our epistemic route to the form of an object is, on this position, 'language first', ${ }^{8}$ for our purchase on the forms of objects is arrived at, in the first instance, through our understanding of syntax.

Wittgenstein emphasises the relationship between names, their syntactical application, and the form of objects where he says, 'We have become clear, then, that names may and do stand for the most various forms, and that it is only the syntactical application that signalises the form that is to be presented' (1961a: p. 59). This sentiment is repeated in the Tractatus: 'A sign does not determine a logical form unless it is taken together with its logico-syntactic employment' (3.327). The view, first presented in the Notebooks, that the form of an object may be gleaned through attending to the syntactical application of the object's name, is, then, clearly maintained in the Tractatus. I am not here claiming that Wittgenstein, in the Tractatus, holds that the form of an object is wholly derived from the syntax of its name. Rather, the form of a sign is only determinate when its 'logico-syntactic employment' is considered, where what ultimately governs the syntactic features a sign possesses remains a further question. Whether the relation of priority with respect to the determination of an item's form runs from language to the world or vice versa is a much-disputed subject; I intend to remain neutral on this issue. My claim is that we may come to appreciate the form of an object through attending to the form of that object's name, where the form of the name is grasped through observation of its syntactic features. This leaves it open that the form of the object may be determined by that of its name, or vice versa.

\subsection{The Reducibility of Form}

The forms of objects, we have seen, are mirrored in the combinatorial capabilities possessed by the names which deputise for them. The form of an object, moreover, is the possibility of its occurring in a state of affairs. Wittgenstein says, 'The determinate way in which objects are connected in a state of affairs is the structure of the state of affairs' (2.032). Wittgenstein also says that 'Form is the possibility of structure' (2.033). The form of an object is 'the possibility of structure' because an object's form is its potential for combining with other objects, and the structure of a state of affairs is the way in which its constituent objects are combined with one another. The form or combinatorial potential of an object is the possibility of structure, for there can be no structure without a combination of objects. There can be no way in which objects are

\footnotetext{
8 In the Notebooks Wittgenstein suggests that the object 'wholly determines' the relation in which it stands to its name (1961a: p. 70). Although our epistemic route is, as I say, 'language first', the nature of language is determined by the form that is common to all possible worlds, on this early view. In other words, the route of epistemic access to an object's form runs in the opposite direction to the relation of priority an object's form has over its name's combinatorial potential in the Notebooks. Both Malcolm (1986: p. 14) and Pears (1987: p. 8) have maintained that Wittgenstein's view in the Tractatus does not change from that of the Notebooks in this respect. Winch (1987: pp. 9-10), Ishiguro (1969: pp. 20-21), and McGuinness (2002b: pp. 82-94) have argued differently. To decide on this matter, however, lies outside of the scope of the current article, and I therefore remain neutral on it for present purposes. See also Johnston (2007: pp. 385-389).
} 
combined without objects' being capable of combination; the possibility of structure $i s$ the potential for objects to combine with one another.

It might be argued ${ }^{9}$ here that the word 'form' in 2.033 refers not to the form of an object, but to the form of a state of affairs, and that it is therefore rash to assume that the sentence 'Form is the possibility of structure' straightforwardly applies to objects. This objection is supported by the consideration that remark 2.033 occurs at the beginning of a series of remarks concerned more squarely with states of affairs than with objects. In my view remark 2.033 is deliberately neutral with respect to its application, and it therefore may be used to describe the forms of objects as well as those of states of affairs. Several considerations join to support this view. Firstly, the wording of the phrase itself is neutral with respect to application; this offers prima facie evidence for the neutral reading. Secondly, 2.033 occurs shortly after Wittgenstein has identified objects with form (2.025). This identification will be explored in further detail, below. Given this identification, though, it would seem that any clear statement as to what form is must be applicable to objects, for objects are 'form and content'. Lastly, Wittgenstein's other, non-neutral, descriptions of 'form' ${ }^{10}$ may each be very naturally understood as instances of this more general characterisation. That Wittgenstein's other descriptions of form are easily assimilable to instances of 2.033 read as a general claim supports our reading that remark as application neutral. I have just explained how 2.033 applies to objects; we shall now see how 2.033 applies to propositions.

Wittgenstein writes:

The fact that the elements of a picture are related to one another in a determinate way represents that things are related to one another in the same way.

Let us call the connexion of its elements the structure of the picture, and let us call the possibility of this structure the pictorial form of the picture. (2.15)

Wittgenstein describes propositions as pictures (4.01). Where the form of an object is the possibility of it combining with others such that the combination in question exhibits a structure, the form of a picture, according to 2.15 , is the possibility of its structure. A picture's structure is 'the connexion of its elements' (2.15). Given that Wittgenstein describes propositions as pictures, we may, on the basis of 2.15 , draw the following conclusion. The form of a proposition is the possibility that its elements stand in relation to one another in the way they do in fact stand, and as the objects for which they deputize must stand if the proposition in question is true. A proposition must share a form with that which it represents in order that it be capable of representing. The form of a proposition is therefore a possibility which is actualised if what it represents exists. Form, as remark 2.033 makes clear, is a modal notion. Form concerns possibilities. Structure, by contrast, is not a modal notion. Structure concerns the way in which things are related, rather than merely the way they might be. ${ }^{11}$ At this stage the following objection may be made to the understanding of

\footnotetext{
9 My thanks to an anonymous referee for raising this issue.

10 See $(2.0141 ; 2.15-2.151)$.

11 This difference in the modal character of form versus the non-modal character of structure is a difference which Black fails to appreciate: 'Wittgenstein's distinction between 'structure' and 'form' has troubled commentators as able as Ramsey. It is doubtful whether it is needed.' (1964: pp. 66). Ramsey, despite
} 
structure here presented. States of affairs may either obtain or not. Moreover, states of affairs exhibit a structure. Consequently, structure must, in opposition to what I have said, be understood in a sense which does not imply that structures are necessarily actual. ${ }^{12}$ Only states of affairs which do in fact obtain, though, exhibit a structure. That obtaining states of affairs exhibit a structure while non-obtaining states of affairs do not follows from Wittgenstein's description of the structure of a state of affairs:

The determinate way in which objects are connected in a state of affairs is the structure of the state of affairs. (2.032)

It is a mistake to suggest that objects may be connected, and that the connection may exhibit a structure, while the state of affairs of which those objects are constituents fails to obtain. There are, accordingly, no non-obtaining states of affairs which exhibit structure.

The form of a proposition is, we have just seen, the possibility of its structure. The form of a proposition is identical with the form of that which it represents. The form of a proposition is the possibility that what it represents obtains, for form is the possibility of structure, and represented items must obtain in order that they exhibit a structure. Wittgenstein writes, 'A picture contains the possibility of the situation that it represents' (2.203). One might characterise the form of a proposition, then, as the possibility of a situation's existing, on the basis that only an existent situation, or obtaining state of affairs, may exhibit a structure. In other words, the possibility of structure involves the possibility of something's existing, for the exhibition of structure demands that the structured item exist. Wittgenstein adopts the terminology of 'existing' and 'non-existing' representations in the following remark:

If an elementary proposition is true, the state of affairs exists: if an elementary proposition is false, the state of affairs does not exist. (4.25)

In the Notebooks Wittgenstein says, 'spatial and logical place agree in both being the possibility of an existence' (1961a: p. 27). Here Wittgenstein identifies the possibility of something existing with a place in either physical or logical space. In the Tractatus Wittgenstein reaffirms this claim: 'In geometry and logic alike a place is a possibility: something can exist in it' (3.411, emphasis added). The form of a proposition is the possibility of something's existing, for form is the possibility of structure, and only existents exhibit a structure. Wittgenstein writes:

The propositional sign with logical co-ordinates - that is the logical place. (3.41)

The propositional sign with its logical co-ordinates is a logical place, according to Wittgenstein. A logical place is the possibility of something's existing in that place, and the form of a proposition is the possibility of something's existing such that the thing in question exhibits a structure. Given these claims, and given that Wittgenstein squarely locates 'the logical place' in the propositional sign with 'logical co-ordinates', it is

Footnote 11 continued

Black's accusation, appears to be in full command of the distinction between form and structure I have emphasised; see Ramsey (1931: pp. 271).

12 My thanks to an anonymous referee for raising this issue. 
plausible that the form of a proposition be identified with a place in logical space. We shall examine Wittgenstein's notion of 'logical co-ordinates' in further detail, below.

Wittgenstein writes

What any picture, of whatever form, must have in common with reality, in order to be able to depict it - correctly or incorrectly - in any way at all, is logical form, i.e. the form of reality. (2.18)

Pictures, then, must have an identical logical form to that which they depict in order that they be capable of depiction at all. Given that the form of a proposition is both a place in logical space and identical to the form of the fact it depicts, it follows that the form of the depicted fact is likewise a place in logical space. What is common to a proposition and the fact it depicts is a certain place in logical space.

Wittgenstein says,

The logical form of the proposition must already be given by the forms of its component parts. (1961a: p. 23)

In the Tractatus Wittgenstein writes

A proposition determines a place in logical space. The existence of this logical place is guaranteed by the mere existence of the constituents - by the existence of the proposition with a sense. (3.4)

The logical form of a proposition is 'given', according to Wittgenstein, by the forms of its component names. The logical form of a proposition is, we have seen, the possibility that what it represents exists. I have, on the basis of remark 3.41 and 3.411, identified such a possibility with a place in logical space. That Wittgenstein says a logical form is given by its components, as well as that a logical place is guaranteed by the existence of constituents, lends further support for this identification. The existence of this place is, Wittgenstein claims, guaranteed by the 'mere existence' of the constituents. It is Wittgenstein's view that we do not require anything over and above the constituents of a proposition in order that the place in logical space determined by that proposition be guaranteed to exist. The form of a proposition, in other words, reduces to its constituents. We must return to Wittgenstein's conception of objectual form in order to see why, in his view, this should be so.

The form of an object, I have emphasised, is the 'possibility of structure' because an object's form is its combinatorial potential, and the exhibition of structure depends upon a combination of objects into the entity whose structure it is. Wittgenstein remarks that, 'If all objects are given, then at the same time all possible states of affairs are given' (2.0124, emphasis original). If some objects are given then their combinatorial potentialities are, necessarily, also given, for their combinatorial potentialities are, we have established, their form. Vitally, combinatorial potentialities are possibilities of structure. ${ }^{13}$ Consequently, as soon as objects are given, possibilities of structure are also given. Wittgenstein says that 'Objects contain the possibility of all situations'

\footnotetext{
13 Where this claim is not to be understood as implying that combinations of objects are identical to structures, but only that the potential for objects to combine is the potential for items, such as states of affairs, to exist and thereby exhibit structure.
} 
(2.014). Places in logical space, being possible situations, are therefore 'contained' in the objects whose combination constitutes the occupation of such a space. Places in logical space, being the forms both of propositions and the items they depict, are contained in objects. The forms of propositions and the items they depict may, consequently, be reduced to the forms of objects.

That Wittgenstein identified the possibilities of combination common to all possible worlds with objects is demonstrated by his saying,

It is obvious that an imagined world, however different it may be from the real one, must have something - a form - in common with it. (2.022, emphasis original)

Objects are just what constitute this unalterable form. (2.023)

Here it will be worthwhile to pause briefly to motivate this reductive approach before describing its character in further detail, for the relevant approach will become important in the final section. It is one of Wittgenstein's most well-known commitments that there are, in the world, simple objects, and that these objects serve as referents for the names of propositions. Just why Wittgenstein held to this view is one of the most controversial areas of Tractatus commentary. Here I shall sketch a rationale for Wittgenstein's commitment to simple objects, and to the reduction of propositional form to those of simple objects. My aim is not to develop a detailed justification for Wittgenstein's commitment to 'substance', ${ }^{14}$ but rather to provide the minimal background required for the reader to accept that Wittgenstein did hold to the relevant view. We shall then be free to explore those characteristics of Wittgenstein's reductive approach which are relevant to the final argument given in Sect. 2. To clarify, my aim is not to provide a novel contribution to the much-discussed debate concerning Wittgenstein's argument for simples, but to give some indication of why he might have adopted a view, the characteristics of which are relevant to an understanding of remark 4.12.

Wittgenstein writes:

Objects make up the substance of the world. That is why they cannot be composite. (2.021)

If the world had no substance, then whether a proposition had sense would depend on whether another proposition was true. (2.0211)

In that case we could not sketch any picture of the world (true or false). (2.0212)

Wittgenstein holds to the following two assumptions: language derives its meaningfulness from a relation with the world (2.1511); a fundamental language-world relation is that of reference (2.1514-2.1515). Wittgenstein terms the referents of names 'objects'. These objects, though, cannot be complex, for if they were, it would be a

\footnotetext{
14 More detailed treatments, including some which expressly deny the correctness of that which I present, may be found in Anscombe (1959: p. 29), Black (1964: pp. 60-61), Carruthers (1990: Ch's 9 \& 10), Hart (1971: pp. 279-281), MacBride (2018: pp. 188-190), Morris (2008: pp. 39-50; 355-364; 2016), Proops (2004), Sluga (2012), Tejedor (2003), White (1973; 2006: pp. 38-44), and Zalabardo (2012; 2015: pp. 243-254).
} 
contingent matter whether or not their components are related to one another as would be required for the existence of the objects in question, and consequently a contingent matter whether or not the names of such complex objects are meaningful. If the meaningfulness of a name depends upon the configuration of a given set of entities, then the meaningfulness of sentences employing that name depend, in an objectionable fashion, on whether or not it is true that such a configuration obtains. What is controversial amongst Tractatus commentators is the precise character of Wittgenstein's objection to this view. Glossing over very many details, we may summarise Wittgenstein's objection as turning on the claim that what we can say is surely independent of what is the case. If the names of our language were threatened with reference-failure in cases where the entities whose combination constitutes the existence of their referents are not combined in the desired manner, then our ability to make claims would be beholden to the contingencies of the world. What we can say isn't beholden in that fashion. Our ability to make claims, whether right or wrong, is not impinged upon by certain other claims' being false. Those referents identified at the terminus of analysis cannot be complex, on pain of depending upon the fortuitous arrangement of their constituent parts in order that they exist. Wittgenstein, in the Philosophical Investigations, presents a summary of the argument for simples in line with that which I have just described ${ }^{15}$ :

But why does it occur to one to want to make precisely this word into a name, when it is evidently not a name?-That is just the reason. For one is tempted to make an objection against what is ordinarily called a name. It may be put like this: a name ought really to signify a simple. And for this one might perhaps give the following reasons: The word "Excalibur", say, is a proper name in the ordinary sense. The sword Excalibur consists of parts combined in a particular way. If they are combined differently Excalibur does not exist. But it is clear that the sentence "Excalibur has a sharp blade" makes sense whether Excalibur is still whole or is broken up. (\$39)

It is a necessary condition on a proposition's making sense that it share a form with that which it represents. That the form of a proposition reduces to the forms of simple objects constitutes an explanation of how that proposition remains meaningful throughout variations in circumstance. In other words, the construal of propositional form as entirely reducible to the forms of simple items guarantees the result that the meaningfulness of a proposition be unaffected by which configurations of objects obtain. This is at least one plausible motivation for the reduction of propositional form to the forms of their elements and to the objects those elements name.

Objects, Wittgenstein emphasises, are the form of the world (2.023). The form of the world is what it has in common with every other possible world. What is common to all possible worlds is the existence of certain places in logical space; the very same places in logical space are common to all possible worlds. In other words, each and every possible world, irrespective of which of its places in logical space are in fact occupied by combinations of objects, contains the same possibilities for objectual

\footnotetext{
15 See also (\$46), and Wittgenstein (1975: p. 72). Indeed, one may cite the similarity between the reading I give and Wittgenstein's later summary as a reason to reject my reading as inaccurate; see, e.g., Mounce (1981: 33), and Zalabardo (2015: pp. 253-254).
} 
combination. Vitally, the same places in logical space are common to all possible worlds because they contain the same objects, and, as we have seen, places in logical space are reducible to the combinatorial potential of objects. The form of the world, indeed of every world, is 'given' by the objects it contains insofar as the form of all worlds is reducible to the combinatorial potential of objects. Anscombe reminds us that 'the original seat of form is the objects themselves [...]' (1959: p. 111). Merrill Hintikka and Jaakko Hintikka similarly write 'One of the most striking doctrines of the Tractatus is that all logical forms can be built up of the forms of simple objects' (9). The totality of places in logical space is reducible to the totality of objects. A place in logical space is reducible to the forms of the objects whose combination constitutes the occupation of that place.

We are now in a position to examine Wittgenstein's claim that 'the logical form of a proposition must already be given by the forms of its component parts' and 'guaranteed by the mere existence' of those parts. The logical form of a proposition is a place in logical space. The place in logical space determined by a proposition is identical to that occupied by the fact it depicts. The place in logical space occupied by a fact is reducible to, or 'given by' the forms of the objects whose combination constitutes that fact. We saw, in $\S 1.1$, that the forms of objects are mirrored by their names. Form, I have emphasised, is combinatorial potential, or the "possibility of structure' (2.033). Objects and their names share combinatorial potential, and the relation of shared combinatorial potential in which they stand is grasped through our attending to the 'logico-syntactic employment' of the names. Importantly, objects and their names, in virtue of their sharing combinatorial potential, share form. The place in logical space determined by a proposition is reducible to the forms of objects whose combination constitutes the occupation of that place. The forms of objects are mirrored in their names. Consequently, the place in logical space determined by a proposition is reducible to the forms of its component names. This is why Wittgenstein says that the logical form of a proposition must already be given by the forms of its component parts, or else the 'mere existence' of its constituents. The logical form of a proposition is reducible to the forms of its component parts, because the forms of its component parts are shared by the objects they name, and the logical form of the proposition in question is reducible to the forms of the relevant objects. My view here echoes that of Peter Sullivan: 'So to talk of the pictorial form of a proposition is to draw attention to the fact that any particular propositional structure is an actualization of possibilities of use built into the forms of its constituent expressions' (Sullivan, 2001: p. 103, emphasis original).

The same point may be re-stated by employing the terminology of co-ordinates, a terminology with which Wittgenstein extends the spatial metaphor so far deployed. Wittgenstein says that 'The propositional sign with logical co-ordinates, that is the logical place' (3.41). The constituents of a proposition may be usefully construed of as 'logical co-ordinates', according to Wittgenstein. In his Notebooks Wittgenstein offers the following example: 'We might conceive two co-ordinates $a_{\mathrm{P}}$ and $b_{\mathrm{P}}$ as a proposition stating that the material point $P$ is to be found in the place $(a b)$.' (1961a: 


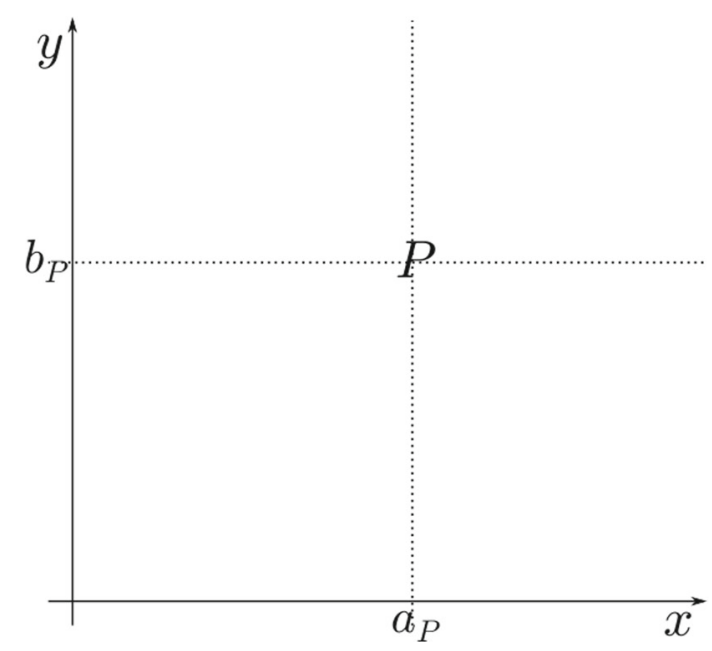

Fig. 1 2-dimensional plot

p. 20). An adaptation of Wittgenstein's example ${ }^{16}$ may be visualised with the aid of a simple plot. It will be necessary to supplement the example with further details as we proceed, and to bear in mind that the language here constructed is both idiosyncratic as well as deficient in certain important ways which will shortly be discussed (Fig. 1).

Let us treat this plot as an object-language proposition which asserts the occupation of the place $\left(a_{\mathrm{P}}, b_{\mathrm{P}}\right)$; the plot, in other words, says that $\left(a_{\mathrm{P}}, b_{\mathrm{P}}\right)$ is occupied by $P$. The intersection of dotted lines constitutes an assertion. As David Pears says

Names are like co-ordinates and what corresponds to uttering a sentence is giving the co-ordinates of a point in space; for example two co-ordinates are needed to fix a point on a map and giving them is like saying ' $\varphi a$ '. (1987: p. 119)

Let us further assume that the place $\left(a_{\mathrm{P}}, b_{\mathrm{P}}\right)$ is occupied by $P$ if and only if two objects, namely $a_{\mathrm{P}}$ and $b_{\mathrm{P}}$, are combined with one another in a certain way. The names of $a_{\mathrm{P}}$ and $b_{\mathrm{P}}$ are not, though, ' $a_{\mathrm{P}}$ ' and ' $b_{\mathrm{P}}$ ', respectively. Rather, the name of $a_{\mathrm{P}}$, as it appears in the relevant proposition is

\footnotetext{
16 What follows is an adaptation, diverging from the example suggested by Wittgenstein's own remarks, in the following sense. In the case I describe it is the plot which says that a state of affairs obtains at place $\left(a_{\mathrm{p}}\right.$, $\left.b_{\mathrm{p}}\right)$. Wittgenstein, by contrast, describes ' $\left(a_{\mathrm{P}}, b_{\mathrm{P}}\right)$ ' as a proposition which says that place $(a, b)$ is occupied by $P$. My proposal involves a specification of a place which includes reference to an occupant $P$, whereas Wittgenstein's specification is, as it were, 'occupant-neutral'. A non-neutral specification here serves to emphasise the relationship between the place and the potential occupant of that place. A place in logical space is not a mere place, it is a place for something; and what a place is for is, in turn, determined by the forms of the objects to which the place in question reduces. It is, as well shall see, an unavoidable deficiency of the conception of object as co-ordinate that given two objects one is given no more than one mode of combination; the specification of an occupant here is therefore a determinate specification. My thanks to an anonymous referee for urging greater clarity here.
} 


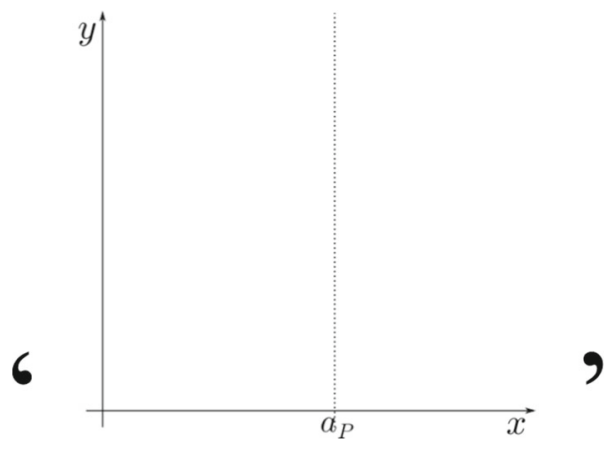

The name of $b_{\mathrm{P}}$ is

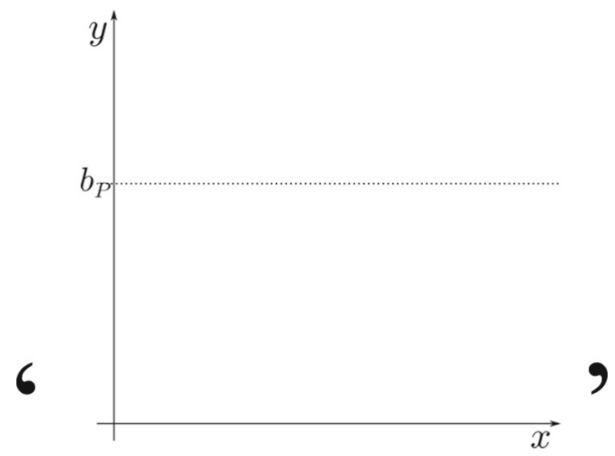

Conceiving of these names as including the axes allows us to more easily treat them as essentially possessing their combinatorial potential, such that two names possessing different capacities for intersection may not count as referring to the same object. ${ }^{17}$ The combining of these names consists, in theory, in superimposing one onto the other, such that both axes of each name align with those of the other name. In practice, combining the names consists simply in adding to the one that which doesn't figure in the other. We may stipulate that no well-formed formula of this two-dimensional language may be constructed in any way other than those two just described. The form, or combinatorial potential, of a name is exhibited through its having the capacity to be intersected by that of another name. The form of a name is perspicuously exhibited in this co-ordinate language, for the points at which a name may be intersected are clearly visible. The entirety of a given name's modal profile is, so to speak, open to view; both its combinatorial potential and its combinatorial limits are easily gleaned. The names of our co-ordinate language wear their forms, as it were, on their sleeves. We need not, for instance, observe category errors in order to see that the name of $a_{\mathrm{P}}$ cannot be intersected by itself. Indeed, no proposition representing the intersection of $a_{\mathrm{P}}$ by itself is even formulable ${ }^{18}$ in this language. The analogue of a category error in

17 It follows that these names are, in at least one sense, not simple. Hintikka and Hintikka (1986: pp. 39-41) argue that Tractarian names need not be conceived of entirely without complexity. It is not necessary though, for my purposes, that I defend Hintikka and Hintikka's position. The co-ordinate language here devised is certainly not adequate for the project of Tractarian analysis, and further shortcomings will be examined below.

18 See Pears (1987: p. 121). 
English for our co-ordinate language consists in the concatenation of two names not capable of intersecting one another. A translation of the sentence ' 4 is heavier than 5' into a co-ordinate language might, for instance, be represented by two names whose dotted lines run parallel to one another. Since only intersections effect an assertion, the relevant translation will be seen straightaway to misfire. Natural languages by contrast do not display the inappropriateness of category errors in as transparent a fashion as does the co-ordinate language.

The possibility of a name's intersecting another is what the existence of a place in logical space comes to. It should be clear, then, that given two suitably combinable names, one is thereby given the potential for two dotted lines to intersect one another, and consequently one is thereby given a place in logical space. Indeed, whenever two or more names are concatenated with one another in a way which effects an assertion, parts of them do intersect one another. The existence of a place in logical space is not an item over and above the potential for linear intersection. Given the two names so far discussed, the place which our example plot claims to be occupied is guaranteed to exist, for the dotted lines figuring in those names are essentially capable of intersecting one another at $\left(b_{\mathrm{P}}, a_{\mathrm{P}}\right)$. Wittgenstein says 'If a point in space does not exist, then its co-ordinates do not exist either, and if the co-ordinates exist then the point exists too. That is how it is in logic.' (1961a: p. 69). If two meaningful names of our co-ordinate language exist, a place in logical space exists, for a place in logical space just is the potential for two names to intersect one another, and the names in question essentially possess this potential. Winch has remarked that

A name and the object to which it refers exist in the same 'logical space'; the name also exists in the same logical space as the other names with which it may significantly combine in propositions; and the object exists in the same logical space as the other objects with which it may combine in facts. Logical space determines what combinations of names (i.e. what propositions) are possible and also what combinations of objects (i.e. what facts) are possible. (1969: p. 5)

This conception of Tractarian logical space is a substantivalist one in which space determines the behaviour of those items which inhabit it. Logical space, on this view, is prior in order of explanation to the combinatorial potential of Tractarian objects and their names. On Wittgenstein's position as I have presented it, by contrast, a 'place in logical space' is nothing over and above the combinatorial potential of the items whose combination constitutes the occupation of that place. There is not a logical aether, in which the objects of the Tractatus find themselves, and from which they derive their form. Rather, the notion of logical space is parasitic on that of objectual form.

Wittgenstein says that the logical form of a proposition is 'given' by the forms of its component parts. Importantly, though, he does not, in the Tractatus, say that the logical form of a proposition is determined by those of its components. Put simply, this is because the forms of the components of a proposition may well 'contain' in their combinatorial potential the possibility of more than one structure. Take, for example the sentence ' $a b c$ ' composed of the name ' $a$ ' of object $a$, ' $b$ ' of $b$, and ' $c$ ' of $c$. Assume that every permutation of these names constitutes a proposition capable of being true and capable of being false. Given the names ' $a$ ', ' $b$ ', and ' $c$ ' a total of six places in logical space are given; six possible combinations are essentially contained in the 
objects for which the names stand. The proposition ' $a b c$ ' determines one of these places. Wittgenstein, in the Notebooks, asks 'How does the proposition determine the logical place? How does the picture present a situation?' (1961a: p. 26). Revealingly, Wittgenstein takes these two questions to be equivalent. In answer he writes

One name is representative of one thing, another of another thing, and they themselves are connected; in this way the whole images the situation - like a tableau vivant.

The logical connexion must, of course, be one that is possible as between the things that the names are representative of, and this will always be the case if the names really are representative of the things. [...] (1961a: p. 26)

This second sentence echoes what we have already observed, namely the impossibility of names possessing a different combinatorial potential to the items they are names of. The first sentence is, roughly, the 'picture theory' of propositions. Propositions determine $a$ place in logical space through their exhibiting component names as related to one another in the way in which the objects they stand for would be related if the place in question was occupied. In other words, propositions determine a place in logical space through their possession of a structure. The place in logical space determined by ' $a b c$ ' is determined through the structure of the proposition's identifying it as opposed to the other five possibilities contained in ' $a$ ', ' $b$ ', and ' $c$ '. The logical form of a proposition, then, is a place in logical space contained in the combinatorial potential of its names. The structure of a proposition contributes to the determination of this place. The possession of a structure is what enables a proposition to say something because it enables the proposition to identify, from the variety of places in logical space contained in the essential combinatorial potential of its constituent names, which of these places it concerns. Richard Gaskin writes

[L]ogical form must be that in virtue of which a sentence manages to say something - is prevented from degenerating into a list of names. [...] For the form of a sentence consists in the fact that its names are configured in a certain way. (2008: pp. 327-328).

Stewart Candlish and Nic Damnjanovic likewise suggest that 'The form of a propositional sign is the way in which its names are combined.' (2012: p. 87). From what I have said, it should be clear both that Candlish and Damnjanovic's, as well as Gaskin's claims here are mistaken. The structure of a proposition, rather than the form, is the way in which its elements are combined. ${ }^{19}$ The form of a proposition consists in the fact that its names can be so configured, but this possibility is not itself sufficient for the existence of a proposition which says something.

Just here a deficiency in our co-ordinate language is brought into view. In order to depict facts consisting of three objects in combination, we should have to extend our co-ordinate language to include a third axis. Take, by way of example, the following proposition of this language asserting that the place $\left(a_{\mathrm{P}}, b_{\mathrm{P}}, c_{\mathrm{P}}\right)$ is occupied (Fig. 2):

\footnotetext{
19 José Zalabardo commits the same error; see (2015: p. 72). Morris observes this feature of Zalabardo's interpretation; see (2012: p. 125).
} 


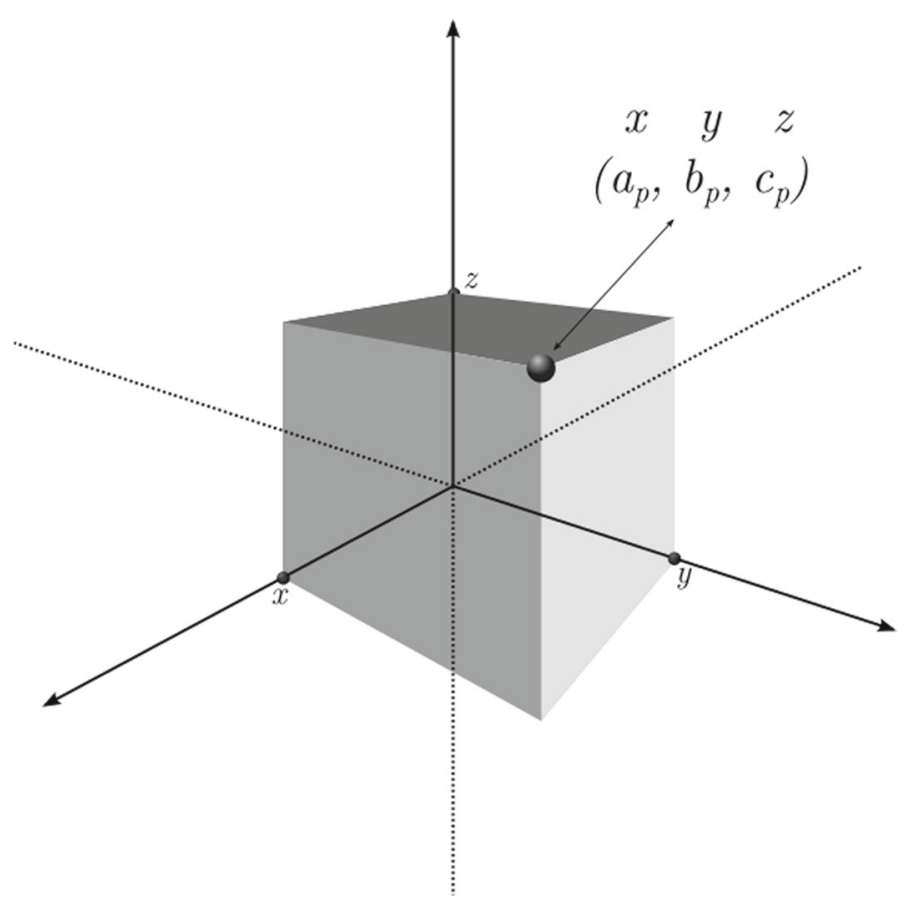

Fig. 2 3-dimensional plot

Given our three co-ordinates, only one point in space is determined by them. The expressive power of this language is therefore extremely limited ${ }^{20}$; no provision is made for the representation of different places in logical space being occupied by facts composed of identical objects. What our co-ordinate language achieves by way of the perspicuous exhibition of objectual form, and concomitantly the making visible of category errors, is offset by a restricted and myopic conception of logical space. White writes

We may then think of a state of affairs as the existence of a Newtonian point mass at a certain position in space-time: we may specify such a position by Cartesian co-ordinates- $(x, y, z, t)$. If we take the objects of the Tractatus, then, to be the planes of space and time instants, we may construe a state of affairs as consisting in the fact that three planes at a certain time intersect at a point mass.

\footnotetext{
$\overline{20}$ Our co-ordinate language so conceived raises a further difficulty insofar as the representation of places in logical space as occupied by facts consisting of $N$ objects requires the availability of $N$ axes. Wittgenstein was agnostic with respect to the issue of how many objects may combine to form a given fact, and countenances the possibility of facts consisting of infinitely many objects where he says 'Even if the world is infinitely complex, so that every fact consists of infinitely many states of affairs and every state of affairs is composed of infinitely many objects, there would still have to be objects and states of affairs' (4.2211) The representation of places in logical space as occupied by facts composed of infinitely many objects requires the availability of infinitely many axes. Mathematicians are familiar with models involving the $N$ th dimension; our co-ordinate language, though, is incapable of being extended in the way required to capture the full gamut of logical space.
} 
[...] Of course, the actual structure of logical space would be much more complicated than that envisaged in this simple model, but I suggest that it would be simply a far more complicated version of this model that would be required if we were to satisfy all the requirements Wittgenstein is arguing for [...]. (2006: p. 46)

White here suggests that a model substantially different from a simple co-ordinate language in degree, but not in kind, is in principle capable of representing the entirety of Tractarian logical space as occupied by facts. White here employs the co-ordinate model of objects in an excessively literal fashion, and consequently his conception of a Tractarian object involves items whose characteristics betray the influence of an analogy whose incidental features have been mistaken for essential ones. It is a consequence of White's view that for any set of objects there is only one possible combination of them, for given any set of co-ordinates, only one point is determined by them; moreover this consequence is obviously not removed by extending our coordinate language to the $N$ th dimension. This conception of an object, though, is unduly restrictive. My contention is not that Wittgenstein's remarks show conclusively that he conceived of objects as capable of combining with one another in more than one way. Rather, it was Wittgenstein's view that the form, or combinatorial potential, of an object may not be settled a priori:

We now have to answer a priori the question about all the possible forms of elementary propositions.

Elementary propositions consist of names. Since, however, we are unable to give the number of names with different meanings, we are also unable to give the composition of elementary propositions. (5.55)

Given what we have seen, namely that the form of a proposition is nothing over and above the forms of its constituent names, our being unable, in Wittgenstein's view, to give the forms of propositions a priori constitutes also the inability to give the forms of a proposition's names a priori. As Colin Johnston says, ${ }^{21}$

There is no saying a priori what forms of elementary propositions there are, and so no saying a priori what types (forms) of names, and so again of objects there are. A demand for an exposition of the logical categories of entity, insofar as that is a request for something to be given a priori, is misguided. (2009: p. 153)

Insofar as White's conception of a Tractarian object rules out a priori the possibility of an object combining with others in more than one way, it represents an interpretation in tension with Wittgenstein's holding that the combinatorial potential of objects is discoverable only a posteriori. The analogy Wittgenstein draws between co-ordinates and names makes the relationship between places in logical space and names perspicuous. A proposition of our co-ordinate language displays clearly how the mere existence of meaningful names suffices for the possibility of their intersecting one another, and consequently how the form of a proposition depends wholly upon the forms of the names whose combination constitutes that proposition. Our co-ordinate language,

$\overline{21}$ See also MacBride (2005: pp. 102-103; 2018: pp. 197-202). 
though, unavoidably exhibits features which we should not impute to Wittgenstein's conception of the relationship between the forms of names, the objects they refer to, and places in logical space. Wittgenstein's employing the terminology of co-ordinates must be treated cautiously if we are not to draw conclusions about the character of Tractarian objects at odds with certain other Tractarian commitments.

\section{Inexpressibility}

Take the following example. Assume that $a$ and $b$ constitute all of the objects there are. The form of a fact or proposition is reducible to the combinatorial potential of its constituents taken severally, rather than to any one constituent in particular. This conclusion is a re-statement of the characterisation of logical form I have been advancing throughout the preceding discussion. The form of a fact or proposition is, as we have seen, a place in logical space reducible to the potential for some items to combine with one another. No single item though, considered wholly in isolation from others, possesses such a potential. In other words, it is bound up with the very notion of combinatorial potential that such a capacity lies not in the existence of a single thing but in several. The combinatorial potential of some items is necessarily dependent upon the existence and character of a plurality. Neither $a$ nor $b$, therefore, may be identified with the form of a fact or proposition. To put the point in linguistic, rather than ontological terms, we might say that the phrase 'logical form' is an incomplete symbol. No thing answers to the phrase, though we may come to understand its meaning through translating statements in which it appears into statements which illustrate the combinatorial potential of several items. ${ }^{22}$ Illustrating the combinatorial potential of several items consists in constructing propositions which make sense, for, as I mentioned at the outset, understanding the ways in which items may or may not combine involves distinguishing sensible assertions from category errors. To attempt the identification of a fact or proposition's constituent with its logical form is to misunderstand the way in which 'logical form' functions as an incomplete symbol. Given that no single constituent of any fact may be identified with its logical form, and given that all objects are essentially possible constituents of facts, ${ }^{23}$ it follows that no object may be identified with the logical form of a fact. Neither $a$, nor $b$, therefore, is the logical form of a fact or proposition.

Assume further that $a$ and $b$ are each capable of combining with one another in exactly two ways: $a b$ and $b a$. The two possibilities of combination just mentioned constitute the whole of logical space, for they constitute all of the possibilities of combination which there are. Crucially, all possible elementary propositions are deter-

\footnotetext{
22 Such statements will not, though, be of the form 'such and such a circumstance is possible'. Rather, they will be ordinary assertions concerning the relatedness of objects. That this was Wittgenstein's view may be seen from the following remark: 'The certainty, possibility, or impossibility of a situation is not expressed by a proposition, but by an expression's being a tautology, a proposition with a sense, or a contradiction' (5.525). Wittgenstein here describes a situation's possibility as something incapable of being 'expressed by a proposition', though expressed by an expression's being a proposition with a sense. In other words, that a proposition possesses a sense itself expresses the possibility of the situation it represents. Hence the absence of modal operators in a language adequate to Tractarian analysis.

23 See (2-2.0121).
} 
mined as soon as these combinatorial possibilities are determined, because elementary propositions must share a form with what they represent in order that they be capable of representing, and forms are combinatorial possibilities. Given the possibilities for objectual combination $a b$ and $b a$, therefore, we are thereby given all of the available elementary propositions there are. The available elementary propositions might be formulated as ' $a b$ ' and ' $b a$ '. We must ask, of these propositions: what do they represent? Unless, within the subject matter of these propositions, the form of a fact or proposition is included, it follows that there is no such thing as making a claim about the form of a fact or proposition through the use of any available elementary propositions.

A proposition represents (darstellen) a 'situation', or a Sachlage (2.203). ${ }^{24}$ Of Sachlagen Wittgenstein says: 'Things [Ding] are independent in so far as they can occur in all possible situations [Sachlagen] [...]' (2.0122), as well as: 'The configuration of objects [Gegenstände] in a situation [Sachlage] corresponds to the configuration of simple signs in the propositional sign' (3.21). Both 'Ding' and 'Gegenstände' are employed synonymously by Wittgenstein as expressions referring to objects (2.01). In both 2.0122 and 3.21, then, Wittgenstein expresses the view that Sachlagen consist of objects. ${ }^{25}$ What a proposition represents (darstellen), then, is a Sachlage, which we may, following 3.21, characterise as a configuration of objects. What a proposition represents is a configuration of objects, by means of a configuration of symbols.

Wittgenstein writes, of substance, that 'It is form and content' (2.025). Objects are form, for the places in logical space constitutive of the 'fixed form' (2.026) of any possible world reduce to their combinatorial potentialities. Objects are content because they are what propositions are about ${ }^{26}$ Propositions represent, in this context, configurations of objects. ${ }^{27}$ That objects may not be identified with the forms of facts or propositions, combined with the claim that it is objects which constitute the subject matter of propositions, explains why forms are not capable of being sensibly discussed through the use of either ' $a b$ ' or ' $b a$ '. Since ' $a b$ ' and ' $b a$ ' constitute all of the available elementary propositions, we may conclude that the logical form of a fact or proposition may not be discussed by any elementary proposition, on Wittgenstein's view.

Where no elementary proposition succeeds in effecting an assertion about a logical form, neither may a compound one. Wittgenstein remarks, in his 'Notes on Logic', that 'what corresponds in reality to compound propositions must not be more than what corresponds to their several atomic propositions. Molecular propositions contain nothing beyond what is contained in their atoms; they add no material information

\footnotetext{
24 Here we must bear in mind Wittgenstein's description of propositions as pictures (4.01), for what 2.203 strictly says is that pictures represent (darstellen) Sachlagen.

25 See also (2.0121).

26 See also (4.122).

27 A context in which darstellen constitutes the relevant operative notion. A separate argument for the conclusion that the subject matter of propositions is the objects named might appeal to remark 2.15. Remark 2.15, though, employs the expression 'stellt vor', where 4.12 employs 'darstellen'. An anonymous reviewer points out that the relevance of 2.15 to 4.12 may not, therefore, be assumed without further argument. Above, I avoid taking a stand on the issue of whether vorstellen, Vorstellung, and vorstellende are interchangeable with darstellen, Darstellung, and dargestellte. See Black (1964: p. 76), Frascolla (2007: pp. 20-21), Phillips (2011: endnote 12), Plourde (2016: p. 97, no. 18; 2017: endnote 5), and Simons (1985: p. 333) for the view that the relevant terms are interchangeable. See Bartunek (forth.: endnote 10) for an opposing view.
} 
above that contained in their atoms' (1961b: p. 100). This reductive approach to truthfunctionality is also made explicit in the Tractatus ${ }^{28}$ :

A proposition is an expression of agreement and disagreement with truthpossibilities of elementary propositions. (4.4)

Truth-possibilities of elementary propositions are the conditions of the truth and falsity of propositions. (4.41)

It immediately strikes one as probable that the introduction of elementary propositions provides the basis for understanding all other kinds of proposition. Indeed the understanding of general propositions palpably depends on the understanding of elementary propositions. (4.411, emphasis original)

As is well-known, quantified propositions may, in Wittgenstein's view, be reduced to truth-functional combinations of elementary ones. ${ }^{29}$ A proposition employing a quantifier cannot, therefore, achieve an expressive feat greater than does the collective effort of those propositions figuring in the truth-functional combination to which the quantificational proposition is reducible. In turn, truth-functionally complex propositions do not express more content than is expressed by those elementary ones occurring as operands. Given that no elementary proposition makes a claim about a logical form, then, we may conclude that no proposition whatever makes such a claim.

What has not yet been explained, however, is Wittgenstein's claim that to represent logical form would require that we 'station ourselves outside logic, that is to say outside the world' (4.12). We have so far identified the forms of propositions with places in logical space. Consequently, we may interpret remark 4.12 as saying that in order to represent places in logical space, we should have to station ourselves outside of logic. A natural query is this: what is logic, such that our ordinary position is inside of it? Early in the Tractatus Wittgenstein says, '[...] Logic deals with every possibility and all possibilities are its facts.' (2.0121). Logic in this context, I submit, is equivalent to the whole of logical space. The whole of logical space consists of all the places in logical space. These places, in turn, are reducible to the forms of objects. What it means to be stationed 'inside' logic is for our position to be inside logical space, where to be positioned inside logical space is simply to be in a position to represent those things and only those things that are possible. To be positioned outside of logical space is, therefore, to be in a position to represent things that are not possible. Given the characterisation just given of what it is to be positioned outside of logical space, we may conclude that there is no such position; we cannot be stationed outside of logic. Wittgenstein takes this line where he says,

It used to be said that God could create anything except what would be contrary to the laws of logic. - The truth is that we could not say what an 'illogical' world would look like. (3.031, emphasis original)

\footnotetext{
${ }^{28}$ For discussions of why Wittgenstein adopted this view see MacBride (2018: p. 215), as well as Sullivan and Johnston (2018: pp. 163-164).

29 See (5.52).
} 
We could not say what an illogical world looked like because we are not, in Wittgenstein's view, in a position to determine, through the use of propositions, places outside of logical space. This is simply because there are no places outside of logical space; logical space by definition consists of all the places there are.

The puzzle which now confronts us is that of understanding precisely why we should have to be positioned 'outside of logic' in order to say things about the logical forms of facts or propositions. The question is this: why should our being able to represent the forms of propositions require that we be in a position, per impossibile, to represent that which lies outside of the totality of logical space? The totality of logical space consists entirely of places in logical space reducible to possibilities for objectual combination. Moreover, what an elementary proposition represents is just such a possible combination of objects, and what it says is that the possibility it represents obtains. In order to say something about the logical form of a fact or proposition, we should have to determine, through the use of a proposition, a place in logical space not reducible to the combinatorial potential of some objects. To see why, we must re-deploy our example of a world in which $a$ and $b$ exhaust the objects, $a b$ and $b a$ exhaust the possibilities for objectual combination, and ' $a b$ ' and ' $b a$ ' exhaust the available elementary propositions. We have seen that what the propositions ' $a b$ ' and ' $b a$ ' represent are that the relevant objects are combined in certain ways. It follows, then, that amongst the available elementary propositions, none makes a claim about either of those combinatorial potentialities which jointly comprise the totality of logical space. Rather, what each of the available elementary propositions say is something about the objects $a$ and $b$. Moreover, and as I have mentioned, no compound proposition contributes any content over and above that expressed by ' $a b$ ' and ' $b a$ '. Any proposition, then, which says something about a logical form can be neither ' $a b$ ' nor ' $b a$ ', nor a compound thereof, for neither of these propositions make a claim of the relevant kind. Any proposition must, if it is to represent anything at all, share a logical form with that which it represents. The only logical forms available, though, are those reducible to the combinatorial potentialities possessed by both $a$ and $b$. Moreover, both of the logical forms available are already in use, as it were, by propositions which do not themselves make claims about logical forms. Consequently, any proposition which does assert a claim about a logical form must itself possess a logical form not reducible to the combinatorial potential of the objects $a$ and $b$. Vitally, there are no combinatorial potentialities not so reducible, for, as Wittgenstein says, 'objects contain the possibility of all situations' (2.014, emphasis added). There are no possibilities to be found in the totality of logical space which are not 'contained' in the combinatorial potential of objects. This is because possibilities, or places in logical space, are reducible to those objects whose combination constitutes the realisation of the relevant possibilities. A proposition which said something about the logical form of a fact or proposition would have to share its form with what it depicts in order that it made sense, and, moreover, its form should have to be a combinatorial possibility not found in logical space. Such a proposition, therefore, would be one which is 'outside of logic', for its form may not be identified with any combinatorial potentiality found 'within' logical space. There is, in other words, no provision for the representation of a logical form to be found in those possibilities reducible to the combinatorial potential 
of objects. The attempt to say something about logical forms, therefore, must fail. Wittgenstein says,

It is as impossible to represent in language anything that 'contradicts logic' as it is in geometry to represent by its co-ordinates a figure that contradicts the laws of space, or to give the co-ordinates of a point that does not exist. (3.032)

The space of possibilities, or the 'points' of our grid, are determined by the objects $a$ and $b$. The attempt to represent a place in logical space which is not determined by those objects, in order to say that such a place is occupied, is therefore tantamount to giving the co-ordinates 'of a point that does not exist'.

I have described this argument through the use of an example in which logical space consists of possibilities reducible to the combinatorial potential of just two objects. The argument, though, is clearly generalisable. Nothing was assumed of either $a$ or $b$ to distinguish them from any other objects. All that was stated of the relevant objects was that neither $a$ nor $b$ themselves count as the logical form of a fact or proposition. This was not a mere stipulation but followed from the conception of logical form I have been advancing throughout this article.

I have aimed to give an interpretation of Wittgenstein's conception of propositional form which contributes to an understanding of remark 4.12. I have described propositional forms as places in logical space reducible to the combinatorial potential of the objects serving as referents of the proposition's names, and determined by a proposition's exhibiting a structure. This understanding of propositional form makes clear the relationship between the forms of objects and the forms of propositions, as well as providing us with the resources to understand 4.12. Remark 4.12, I have shown, constitutes an argument to the effect that the representation of propositional forms would require the determination of a place in logical space not reducible to the combinatorial potential of some objects. There are no such places in logical space not so reducible, and consequently we cannot, according to Wittgenstein, represent propositional forms.

Open Access This article is licensed under a Creative Commons Attribution 4.0 International License, which permits use, sharing, adaptation, distribution and reproduction in any medium or format, as long as you give appropriate credit to the original author(s) and the source, provide a link to the Creative Commons licence, and indicate if changes were made. The images or other third party material in this article are included in the article's Creative Commons licence, unless indicated otherwise in a credit line to the material. If material is not included in the article's Creative Commons licence and your intended use is not permitted by statutory regulation or exceeds the permitted use, you will need to obtain permission directly from the copyright holder. To view a copy of this licence, visit http://creativecommons.org/licenses/by/4.0/.

\section{References}

Anscombe, G. E. M. (1959). An introduction to Wittgenstein's Tractatus. Hutchinson.

Bartunek, N. (2021). Wittgenstein and formal semantics: A case study on the Tractarian notions of truthconditions and compositionality. History and Philosophy of Logic (forthcoming).

Black, M. (1964). A companion to Wittgenstein's Tractatus. Cornell University Press.

Candlish, S., \& Nic, D. (2012). The 'Tractatus' and the unity of the proposition. In Jl. Zalabardo (Ed.), Wittgenstein's early philosophy. Oxford University Press.

Carruthers, P. (1990). The metaphysics of the Tractatus. Cambridge University Press. 
Frascolla, P. (2007). Understanding Wittgenstein's Tractatus. Routledge.

Gaskin, R. (2008). The unity of the proposition. Oxford University Press.

Hacker, P. M. S. (1986). Insight and illusion: Themes in the philosophy of Wittgenstein. Oxford University Press.

Hart, W. D. (1971). The whole sense of the Tractatus. Journal of Philosophy, 68(9), 273-288.

Hintikka, M. B., \& Hintikka, J. (1986). Investigating Wittgenstein. Wiley.

Ishiguro, H. (1969). Use and reference of names. In P. Winch (Ed.), Studies in the philosophy of Wittgenstein (pp. 20-50). Routledge.

Johnston, C. (2007). Symbols in Wittgenstein's Tractatus. European Journal of Philosophy, 15(3), 367-394.

Johnston, C. (2009). Tractarian objects and logical categories. Synthese, 167(1), 145-161.

Kenny, A. (1973). Wittgenstein. Penguin.

MacBride, F. (2005). Ramsey on universals. In H. Lillehammer \& D. H. Mellor (Eds.), Ramsey's legacy (pp. 83-104). Cambridge University Press.

MacBride, F. (2018). On the genealogy of universals: The metaphysical origins of analytic philosophy. Oxford University Press.

Malcolm, N. (1986). Nothing is hidden: Wittgenstein's criticism of his early thought. Wiley.

McGuinness, B. (2002a). Pictures and form. In B. McGuinness (Ed.), Approaches to Wittgenstein (pp. 61-81). Routledge.

McGuinness, B. (2002b). The so-called realism of the Tractatus. In B. McGuinness (Ed.), Approaches to Wittgenstein (pp. 82-94). Routledge.

Morris, M. (2008). Wittgenstein and the Tractatus. Routledge.

Morris, M. (2016). The substance argument of Wittgenstein's tractatus. Journal for the History of Analytical Philosophy, 4(7), 1-13.

Morris, M. (2017). Representation and reality in Wittgenstein's tractatus. Teorema, 36(2), 123-133.

Mounce, H. O. (1981). Wittgenstein's Tractatus: An introduction. Wiley.

Pears, D. (1987). The false prison: A study of the development of Wittgenstein's philosophy (Vol. 1). Clarendon Press.

Phillips, D. M. (2011). Wittgenstein's ‘picture theory' and the æsthetic experience of clear thoughts. In Image and imaging in philosophy, science and the arts: Publications of the Austrian Ludwig Wittgenstein society-N.S. 17 (pp. 143-161). De Gruyter.

Plourde, J. (2016). States of affairs, facts, and situations in Wittgenstein's Tractatus. Philosophia, 44(1), 181-203.

Plourde, J. (2017). Wittgenstein's picture theory and the distinction between representing and depicting. International Journal of Philosophical Studies, 25(1), 16-39.

Proops, I. (2004). Wittgenstein on the substance of the world. European Journal for Philosophy, 12(1), $106-126$.

Ramsey, F. (1931). The foundations of mathematics and other logical essays. In R. B. Braithwaite (Ed.), With a preface by G.E. Moore. Kegan Paul, Trench, Trubner, \& Co.

Simons, P. (1985). The old problem of complex and fact. In Simons, P.M. (Eds.), Philosophy and logic in Central Europe from Bolzano to Tarski. Selected essays (pp. 319-338), Dordrecht: Kluwer, 1992. Reprinted from Theoria, 2, 205-225.

Sluga, H. (2012). Simple objects: Complex questions. In J. L. Zalabardo (Ed.), Wittgenstein's early philosophy (pp. 99-118). Oxford University Press.

Sullivan, P. (2001). A version of the picture theory. In W. Vossenkuhl (Ed.), Wittgenstein: Tractatus Klassiker Auslegen (pp. 89-110). Akademie Verlag.

Sullivan, P., \& Johnston, C. (2018). Judgements, facts and propositions: Theories of truth in Russell, Wittgenstein and Ramsey. In M. Glanzberg (Ed.), The Oxford handbook of truth (pp. 150-192). Oxford University Press.

Tejedor, C. (2003). Sense and simplicity: Wittgenstein's argument for simple objects. Ratio, 16(3), $272-289$.

White, R. (1973). Can whether one proposition makes sense depend on the truth of another? Royal Institute of Philosophy Lectures, 7, 14-29.

White, R. (2006). Wittgenstein's Tractatus Logico-Philosophicus. Continuum.

Winch, P. (1969). Introduction: The unity of Wittgenstein's philosophy. In P. Winch (Ed.), Studies in the philosophy of Wittgenstein (pp. 1-19). Routledge.

Winch, P. (1987). Trying to make sense. Wiley. 
Wittgenstein, L. (1921). Tractatus Logico-Philosophicus, 1922, C. K. Ogden (trans.), London: Routledge \& Kegan Paul. Originally published as "Logisch-Philosophische Abhandlung". In Annalen der Naturphilosophische, XIV (3/4), 1921.

Wittgenstein, L. (1961a) Notebooks-1914-1916. In von Wright, G. H., Anscombe, G. E. M. (Eds.), Wiley.

Wittgenstein, L. (1961). Tractatus Logico-Philosophicus, trans. D. F. Pears and B. F. McGuinness. Routledge and Kegan Paul.

Wittgenstein, L. (1975). Philosophical remarks, trans. R. Hargreaves and R. White. Wiley.

Wittgenstein, L. (2006). Philosophical investigations, trans. G. E. M. Anscombe. 3rd edn. Wiley.

Wittgenstein, L. (1961b). 'Notes on logic', appendix I. In G. H. von Wright \& G. E. M. Anscombe (Eds.), Notebooks, 1914-1916 (pp. 93-106). Wiley.

Wittgenstein, L. (1961c). 'Notes dictated to G. E. Moore in Norway', appendix II. In G. H. von Wright \& G. E. M. Anscombe (Eds.), Notebooks, 1914-1916 (pp. 107-118). Wiley.

Zalabardo, J. (2012). Reference, simplicity and necessary existence in the Tractatus. In J. L. Zalabardo (Ed.), Wittgenstein's early philosophy (pp. 119-150). Oxford University Press.

Zalabardo, J. (2015). Representation and reality in Wittgenstein's Tractatus. Oxford University Press.

Publisher's Note Springer Nature remains neutral with regard to jurisdictional claims in published maps and institutional affiliations. 